\title{
Gender Differences in Best Friendships ${ }^{1}$
}

\author{
Leigh E. Elkins \\ Vanderbilt University \\ Christopher Peterson ${ }^{2}$ \\ University of Michigan
}

Prior investigations of friendship patterns have reported gender differences, with women's same-gender friendships tending to be richer and having a possible therapeutic value, as compared to those of men. Compared to same-gender best friendships, opposite-gender best friendships have been described as less fulfilling for women and more fulfilling for men. The present study explored such differences more fully in a sample of 65 female and 58 male predominantly white college students. Subjects completed four modified versions of $P$. H. Wright's [(1985) "The Acquaintance Description Form," In S. F. Duck and D. Pearlman (Eds.), Understanding Personal Relationships: An Interdisciplinarian Approach, London: Sage] Acquaintance Description Form, describing their actual and ideal same-gender best friendships and their actual and ideal opposite-gender best friendships. They also responded to several measures of dysphoria. In the present study, the lowest scores for the friendship scales were reported by male subjects describing same-gender friendships, both ideal and actual. For both male and female subjects, dysphoria was positively correlated with a discrepancy between ideal and actual friendships with same-gender or opposite-gender individuals.

\footnotetext{
${ }^{1}$ This paper is based on an honor's thesis in psychology submitted to the University of Michigan by the first author under the supervision of the second author.

${ }^{2}$ To whom correspondence should be addressed at Department of Psychology, University of Michigan, 580 Union Drive, Ann Arbor, MI 48109-1346.
} 
In the past, both the general population and the social science community assumed that women's friendships were inferior to those of men (see Tiger, 1969; Wright, 1982). More recent discussions questioned this assumption (e.g., Bell, 1981; Davidson \& Packard, 1981; Lenz \& Myerhoff, 1985; Rose, 1985; Rose \& Roades, 1987; Smith-Rosenberg, 1975). Recognizing the need for clarification, Wright (1982) conducted one of the first investigations of gender differences in friendships. He concluded that the evidence did not support the assumption that women's friendships were inferior to those of men. Subsequent researchers took a more analytic approach, seeking to understand which specific aspects of friendship differed along gender lines and which did not.

Several conclusions emerged from this research (Aukett, Ritchie, \& Mill, 1988; Barth \& Kinder, 1988; Caldwell \& Peplau, 1982). Men and women seem not to differ in the quantitative aspects of their friendships, such as number of friends or amount of time spent with them. Both men and women prefer intimate friendships. But there are differences in the kinds of interactions that men and women have with their friends. Women more often than men report that they value and prefer conversation and discussion of personal topics. Men, on the other hand, more often report a preference for the pursuit of activities.

Perhaps unsurprising is the further finding that women tend to regard their same-gender friendships as closer and more satisfying than do men (Becker, 1987; Bell, 1981; Caldwell \& Peplau, 1982; Fischer \& Narus, 1981; Hacker, 1981; Rose, 1985; Safilios-Rothschild, 1981). Indeed, men describe their cross-gender relations as closer than their same-gender ones, whereas women describe their same-gender ones as closer. Said another way, friendships with women are seen as closer, by both men and women (Reis, Senchak, \& Solomon, 1985; Wright \& Scanlon, 1991). Some have concluded that women's same-gender friendships may have a therapeutic component, because of the intimacy and empathetic understanding that characterizes them (Aukett et al. 1988; Buhrke \& Fuqua, 1987). Men may not reap this benefit in their same-gender friendships.

\section{The Present Study}

Although the literature just reviewed seems to point to rather consistent conclusions concerning gender differences in friendship patterns, few studies have asked the same groups of female and male subjects about their same-gender and opposite-gender friends (but see Helgeson, Shaver, \& Dyer, 1987; Wright \& Scanlon, 1991). Almost no studies have asked subjects about their ideals for these friendships, although speculation about ideal standards has been common. 
Male and female subjects in the present study completed questionnaires about their actual and ideal same- and opposite-gender friendships, allowing for a more comprehensive comparison and contrast than research in the past. Subjects responded to versions of Wright's (1985) friendship scales, which encompass a range of ways in which friendships may differ. Table I contains brief descriptions of these ten scales. Subjects also responded to questions concerning depressive symptoms, self-esteem, life satisfaction, and feelings of support.

We were interested in comparing how men and women regarded their ideal same-gender and opposite-gender friendships. One possible prediction, based on the literature just reviewed, is that the highest ideals will be reported by women for their same-gender friendships. Then again, because these are idealizations, perhaps everyone will report the same high standards. Thus, there will be few differences between men and women, or between same-gender and opposite-gender ideals.

We were also interested in comparing how men and women regarded their actual same-gender and opposite-gender friendships. We had three expectations. First, women will describe their same-gender friendships more positively than do men. Second, women will be more satisfied with their same-gender friendships than with their opposite-gender friendships. Third, men will be more satisfied with their opposite-gender friendships than with their same-gender friendships. So, as Reis et al. (1985) previously reported, friendships will be more satisfying to the degree that they involve at least one female.

Because subjects described both their ideal and actual friendships, we were able to calculate discrepancies between these descriptions. An additional purpose of the present study was therefore to compare men and women with regard to these discrepancies. If men and women have similar ideals for friendship, then discrepancies will be greater for men than women, because women are expected to be more satisfied with their actual friendships. But if men's ideals are lower than those of women, then discrepancies will be similar.

Finally, we were interested in the relationship between dysphoria and these various friendship ratings. If friendships are therapeutic, as past investigators have proposed, then individuals who lack a satisfying best friendship will experience higher levels of dysphoria than those who have more satisfactory relationships. If close friendships are in particular therapeutic for women, then this pattern will hold more strongly for women than for men, especially with regard to same-gender friendships (see Aukett $e t$ al., 1988; Buhrke \& Fuqua, 1987). 
Table I. Wright's Acquaintance Description Form Scales

Declaration of Liking

Degree to which subject and target person (TP) declare their personal feelings regarding the friendship.

Example: TP and I often tell each other how much our friendship means to us.

\section{Self-Disclosure}

Degree to which the subject shares his or her personal feelings and problems in the friendship.

Example: When I have a problem, I discuss it with TP.

\section{Salience of Emotional Expression}

Degree to which overt expressions of positive affect are regarded as an essential part of the friendship.

Example: When TP and I get together, we spend a certain amount of time talking about the good feelings and emotions that are associated with our relationship.

\section{Ego Support Value}

Degree to which a subject regards an acquaintance as supportive, nonthreatening, and in general, as behaving in ways to help the subject maintain an impression of himself or herself as a competent worthwhile person.

Example: If I accomplish something that makes me look especially competent or skillful, I can count on TP to notice it and appreciate my ability.

\section{General Favorability}

Degree to which subjects respond to their respective target persons in globally favorable ways.

Example: TP is a genuinely likable person.

\section{Person-Qua-Person Factor.}

Degree to which two individuals react to one another as unique, genuine, and irreplaceable in the relationship. They react to one another on an individualized basis rather than mere role occupants or packages of discrete attributes.

Example: If TP were to move away or "disappear" for some reason, I would really miss the special kind of company s/he provides. 
Table I. Continued

\section{Self-Affirmation Value}

Degree to which a subject regards an acquaintance as behaving in ways that facilitate the subject's recognition and expression of his or her more important and highly valued self-attributes.

Example: TP makes it easy for me to express my most important personal qualities in my everyday life.

\section{Security Value}

Degree to which a subject regards an acquaintance as safe and nonthreatening due to his or her disinclination to behave in ways that would betray trust, cause embarrassment, or draw attention to the subject's points of weakness or self-doubt.

Example: I can converse freely and comfortably with TP without worrying about being teased or criticized if I unthinkingly say something pointless, inappropriate, or just plain silly.

\section{Stimulation Value}

Degree to which a subject regards an acquaintance as interesting and stimulating, and as capable of fostering an expression or elaboration of the subject's knowledge, perspectives, or repertoire of favored activities.

Example: TP can come up with thoughts and ideas that give me new and different things to think about.

\section{Utility Value}

Degree to which a subject regards an acquaintance as willing to use his or her time and personal resources to help the subject meet needs or to reach personal goals.

Example: If I were short of time or faced with an emergency I could count on TP to help with errands and chores to make things as convenient for me as possible.

\section{METHOD}

\section{Subjects}

Respondents were 65 female and 58 male undergraduate students from introductory psychology classes at the University of Michigan, ranging in age from 17 to 29 , with a mean age of 19 . They were mostly first-year students and sophomores whose participation satisfied a course requirement. All but one described themselves as single (i.e., neither married nor living with a partner). The vast majority of subjects (over 90\%) were white. 
Subjects were not asked about their sexual orientation. They were asked if they were romantically involved with the individuals they described as their best same-gender and opposite-gender friends. One male subject reported a romantic relationship with his same-gender best friend; no female subjects reported a same-gender romance. Twenty-seven male subjects $(47 \%)$ and 29 female subjects $(45 \%)$ reported a romance with their opposite-gender best friend.

\section{Measures and Procedure}

In groups of approximately 20 subjects at a time, respondents were asked to complete questionnaires asking about demographics, family ties, how supported they felt in general by family and friends ( 20 questions rated on 7-point scales, ranging from 1 to 7 ), and degree of satisfaction with their lives at the present ( 5 questions rated on 7-point scales, ranging from 1 to 7). Also included were the Beck (1967) Depression Inventory and the Rosenberg (1979) Self-Esteem Scale. The Beck Depression Inventory contains 21 items, each scored 0-3; summed scores range, therefore, from 0 to 63 . The Rosenberg Self-Esteem Inventory contains 10 items, each scored $1-4$; summed scores thus range from 10 to 40 .

For each subject, an overall "dysphoria" rating was created by normalizing and then combining responses to the Beck Depression Inventory (mean $=7.46, S D=6.57$ ), Rosenberg's Self-Esteem Scale (mean $=32.49$, $S D=4.87$ ), and the questions concerning general life satisfaction (mean = 23.95, $S D=6.28$ ) and feelings of support and interconnectedness (mean $=$ $63.32, S D=9.10$ ). The reliability of this composite measure was .82 , estimated by Cronbach's (1951) coefficient alpha. (The same patterns of results were found when analyses were done with the individual scales as with the dysphoria composite.)

Respondents also completed four versions of a best-friend questionnaire, each time with a different target in mind: (a) their present samegender best friend; (b) their present opposite-gender best friend; (c) their hypothetical ideal same-gender best friend; and (d) their hypothetical ideal opposite-gender best friend. The questionnaire was a modified version of Wright's (1985) Acquaintance Description Form (ADF), and assessed the relationship in terms of the ten dimensions described in Table I. Three to six questions comprised each dimension. Questions were answered on 7point scales, ranging from 0 to 6 .

Each of the ten scales was then separately scored for the respondent's four target persons: the actual same-gender best friend, the actual oppositegender best friend, the ideal same-gender best friend, and the ideal opposite- 
gender best friend. The reliabilities of these scales showed a considerable range, from .17 to .91 , with a median of .66 . Because these reliabilities were somewhat low, and because the scales were substantially intercorrelated, a single score was formed for each target person by averaging all 49 items on the ADF. Reliabilities of these composite scales were highly satisfactory: .92 for actual same-gender friend, .95 for actual opposite-gender friend, .88 for ideal same-gender friend, and .88 for ideal opposite-gender friend. (The same patterns of results were found when analyses were done with the individual scales as with the ADF composite.)

A discrepancy score was then calculated between the ideal and actual best friendships, separately for same-gender and opposite-gender targets, by taking the absolute value of the difference between the appropriate scores. High discrepancy scores indicate a mismatch between actual friendships and ideals. As might be expected, the majority of the discrepancies were due to higher scores for the ideal than the actual, but in some number of cases, the opposite pattern occurred (8\% of same-gender friendships, $15 \%$ of opposite-gender friendships). (An attempt was made to characterize those individuals who described actual friendships as more satisfactory than their ideals by comparing them to the other subjects. Small sample sizes limited the power of these comparisons, but there were no apparent differences with respect to dysphoria or demographics. As would be expected, subjects with negative discrepancies tended to rate ideal friendships somewhat lower than did the other subjects and actual friendships somewhat higher.) Men and women did not differ in this tendency to report higher scores for actual friendships than for ideal friendships.

\section{RESULTS}

Overall, the lowest scores were reported by male subjects describing same-gender friendships, both ideal and actual. For both male and female subjects, dysphoria was positively correlated with a discrepancy between ideal and actual friendships.

\section{Ideal Friendships}

For the friendship scale concerning ideal friendships, a two-factor analysis of variance (ANOVA) was computed with gender of subject as a between-subjects factor and type of friendship (same-gender vs. oppositegender) as a within-subjects factor. Mean scores are shown in Table II. 
The main effects of subject gender $(F=9.61, p<.002)$ and type of friendship $(F=21.45, p<.001)$ were both significant, but these are best interpreted in terms of the significant interaction between the two $(F=47.79$, $p<.001)$. As Table II suggests and pairwise tests confirmed $(p s<.001)$, the scores for men describing their same-gender ideal friendships were lower than the scores for the other three conditions, none of which differed from each other.

\section{Actual Friendships}

Similarly, for the friendship scale concerning actual friendships, a twofactor ANOVA was computed with gender of subject as a between-subjects factor and type of friendship (same-gender vs. opposite-gender) as a withinsubjects factor. Mean scores are shown in Table II.

Again, the main effects of subject gender $(F=5.99, p<.003)$ and type of friendship $(F=14.89, p<.001)$ were both significant, as was their interaction $(F=8.80, p<.004)$. The scores for men describing their samegender actual friendships were lower than the scores for the other three conditions $(p s<.001)$, none of which differed from each other.

\section{Discrepancies}

For discrepancies between ideal and actual friendships, a two-factor ANOVA was computed with gender of subject as a between-subjects factor and type of friendship (same-gender vs. opposite-gender) as a within-subjects factor. Mean scores are shown in Table II. There were no significant effects, meaning that the discrepancy between actual and ideal friendships was comparable across male and female subjects describing their same-gender and opposite gender friendships.

\section{Romantic vs. Platonic Friendships}

Subjects indicated whether they were currently involved in a romantic relationship with either of the target individuals they described on the ADF. When the previously described analyses were repeated using just subjects in a platonic relationship with their opposite-gender best friend, the same pattern of results was obtained. And when these analyses were repeated using just subjects in a romantic relationship with their opposite-gender best friend, the same pattern of results was again obtained. Thus, the low scores for malemale friendships relative to other friendships occurred whether or not these other friendships entailed a (heterosexual) romantic relationship. 
Table II. Female vs. Male Friendships ${ }^{a}$

\begin{tabular}{|c|c|c|c|c|c|c|c|c|}
\hline \multirow[b]{3}{*}{ Scale } & \multicolumn{4}{|c|}{ Women $(n=65)$} & \multicolumn{4}{|c|}{ Men $(n=58)$} \\
\hline & \multicolumn{2}{|c|}{$\begin{array}{c}\text { Same- } \\
\text { Gender }\end{array}$} & \multicolumn{2}{|c|}{$\begin{array}{c}\text { Opposite- } \\
\text { Gender }\end{array}$} & \multicolumn{2}{|c|}{$\begin{array}{c}\text { Same- } \\
\text { Gender }\end{array}$} & \multicolumn{2}{|c|}{$\begin{array}{c}\text { Opposite- } \\
\text { Gender }\end{array}$} \\
\hline & Mean & (SD) & Mean & (SD) & Mean & $(\mathrm{SD})$ & Mean & (SD) \\
\hline Ideal & $5.11 a$ & $(0.38)$ & $5.13_{a}$ & $(0.37)$ & $4.77_{b}$ & $(0.49)$ & $5.09_{a}$ & $(0.36)$ \\
\hline Actual & $4.49_{a}$ & $(0.62)$ & $4.55 a$ & $(0.70)$ & $3.96_{b}$ & $(0,60)$ & $4.46 a$ & $(0.84)$ \\
\hline Discrepancy & $0.69_{a}$ & $(0.59)$ & $0.72_{a}$ & $(0.67)$ & $0.85_{a}$ & $(0.52)$ & $0.69_{a}$ & $(0.72)$ \\
\hline
\end{tabular}

${ }^{a}$ Means in a row with different subscripts are significantly different $(p<.05)$ from one another.

Did individuals describe their best friends differently if the relationship were romantic versus platonic? ANOVAs were computed on actual scores, ideal scores, and discrepancy scores for opposite-gender friends with gender of subject and type of friendship (romantic vs. platonic) as betweensubjects factors. Actual friends were rated higher when subjects were involved in a romance with them as opposed to not (4.94 vs. $4.12, F=47.52$, $p<.001)$. However, there were no other effects.

\section{Dysphoria}

Women and men did not differ with respect to dysphoria. [Females and males did not differ on average with respect to the individual measures in the dysphoria composite, except for the questions about general life satisfaction, where females scored somewhat higher than males $(25.03$ vs. $22.74, t=2.04, p<.04)$.] We correlated the dysphoria scale with the discrepancy scores for the friendship scales, separately for women and men. For both female and male subjects, higher levels of dysphoria were associated with greater discrepancies between the ideal and the actual for opposite-gender friendships (female $r=.20, p<.10$; male $r=.26, p<.05$ ). Correlations between dysphoria and discrepancies with regard to same-gender friendships were also found for both female and male subjects (female $r=.33, p<.01$; male $r=.29, p<.03$ ). None of these correlations was significantly different from one another, meaning that a discrepancy between actual and ideal friendships was associated with dysphoria regardless of the gender of the subject or the friend. 
Correlations between the demographic data and the dysphoria scale revealed negative correlations between dysphoria and how many people subjects had met since coming to college $(r=-.27, p<.01)$, how often they called home $(r=-.19, p<.05)$, feeling more emotional support from both male and female friends $(r \mathrm{~s}=-.35$ and $-.51, p \mathrm{~s}<.001)$, parents $(r=-.35$, $p<.001)$, and relatives $(r=-.34, p<.001)$. These correlations were not influenced by gender of subject, and they imply that one's degree of social isolation is linked to dissatisfaction, whether one is a female or a male.

\section{DISCUSSION}

The overall thrust of the present results was quite clear. Actual friendships that involved at least one woman were more satisfying than friendships that did not. The consistently least satisfying friendships described were those between two men, a finding reported earlier in a diary study by Reis et al. (1985). Women's friendships with other women were not more satisfying than their friendships with men. Recent theorizing in the area of friendship has focused on the special character of female-female friendships, but the present results point to a different interpretation. There was no asymmetry here between how women and men regarded their oppositegender friendships (Wright \& Scanlon, 1991).

A special feature of the present research was asking women and men about their standards for ideal friendships, both same gender and opposite gender. Differences here paralleled those found for actual friendships. Ideal standards were consistently lowest for male-male friendships. For the most part, women held equally high standards for their friendships with women and men, standards expressed as well by men for their friendships with women.

The possible relationship between actual vs. ideal friendships is intriguing. Do men express lower standards for their same-gender friendships because they expect not to achieve them? Or does the failure to achieve satisfying relationships with other men lead them to lower their expectations? A longitudinal study of friendship development might shed some light on these questions.

Discrepancies between what people expected in a friendship and what they actually found were correlated with feeling unhappy. Even in the case of male-male friendships, which were held to relatively lower standards, a failure to approach even these modest ideals was associated with dysphoria. This finding is at odds with our speculation that men may not rely on their same-gender friendships for emotional support. Even though men's samegender friendships have been described as activity oriented, a supportive function need not be precluded. 
The demographic factors correlated with dysphoria were the degree to which the respondent felt supported by parents, relatives, and close male and female friends. Further, dysphoria was not associated with the sheer number of friends or relatives, but rather with the degree of support and understanding the respondent felt from them. Dysphoria was also negatively correlated with how often the respondent called home per week. This not only points to social support as being a staple for psychological wellbeing, but to the importance of home and family, in particular.

There are of course limitations to this investigation that need to be acknowledged. The subjects were of a particular age, race, education, and socioeconomic level. Although some researchers have found no differences between undergraduates and other adult populations in terms of same-gender friendship patterns (e.g., Wright, 1982), the generality of the present findings to other populations remains unknown. Another problem with the present study is that the ADF used to elicit descriptions of actual and ideal friendships may be more sensitive to the nuances of friendships involving women (see Table I), which might explain why men's same-gender friendships were consistently rated low. Longitudinal and observational methods encompassing the full range of friendship dimensions would provide a more complete view.

In sum, the present research makes a contribution to our knowledge of friendship by showing that of the possible "best" friendships between people, all combinations except male-male were held to the same high standards and achieved to the same degree. Same-gender friendships among men were consistently the least satisfying, but at the same time, they were held to the lowest standards.

\section{REFERENCES}

Aukett, R., Ritchie, J., \& Mill, K. (1988). Gender differences in friendship patterns. Sex Roles, 19, 57-67.

Barth, R. J., \& Kinder, B. N. (1988). A theoretical analysis of sex differences in same-sex friendships. Sex Roles, 19, 343-363.

Beck, A. T. (1967). Depression: Clinical, experimental, and theoretical aspects. New York: Hoeber.

Becker, C. S. (1987). Friendship between women: A phenomenological study of best friends. Journal of Phenomenological Psychology, 18, 59-72.

Bell, R. R. (1981). Friendships of women and men. Psychology of Women Quarterly, 5, 403-417.

Buhrke, R. A., \& Fuqua, D. R. (1987). Sex differences in same- and cross-sex supportive relationships. Sex Roles, 17, 339-352.

Caldwell, M. A., \& Peplau, L. A. (1982). Sex differences in same-sex friendship. Sex Roles, $8,721-732$.

Cronbach, L. J. (1951). Coefficient alpha and the internal structure of tests. Psychometrika, $16,297-334$ 
Davidson, S., \& Packard, T. (1981). The therapeutic value of friendships between women. Psychology of Women Quarterly, 5, 495-510.

Fischer, J. L., \& Narus, L. R., Jr. (1981). Sex roles and intimacy in same sex and other sex relationships. Psychology of Women Quarterly, 5, 444-455.

Hacker, H. M. (1981). Blabbermouths and clams: Sex differences in self-disclosure in same-sex and cross-sex dyads. Psychology of Women Quarterly, 5, 385-401.

Helgeson, V. S., Shaver, P., \& Dyer, M. (1987). Prototypes of intimacy and distance in same-sex and opposite-sex relationships. Journal of Social and Personal Relationships, 4, 195-223.

Lenz E., \& Myerhoff B. (1985). The feminization of America. Los Angeles: Tarcher.

Reis, H. T., Senchak, M., \& Solomon, B. (1985). Sex differences in the intimacy of social interaction: Further examination of potential explanations. Journal of Personality and Social Psychology, 48, 1204-1217.

Rose, S. M. (1985). Same and cross-sex friendships and the psychology of homosociality. Sex Roles, 12, 63-74.

Rose, S. M., \& Roades, L. (1987). Feminism and women's friendships. Psychology of Women Quarterly, 11, 243-254.

Rosenberg, M. (1979). Conceiving the self. New York: Basic Books.

Safilios-Rothschild, C. (1981). Toward a social psychology of relationships. Psychology of Women Quarterly, 5, 377-383.

Smith-Rosenberg, C. (1975). The female world of love and ritual: Relations between women in the nineteenth century America. Signs, 9, 225-254.

Tiger, L. (1969). Men in groups. New York: Random House.

Wright, P. H. (1982). Men's friendships, women's friendships and the alleged inferiority of the latter. Sex Roles, 8, 1-20.

Wright, P. H. (1985). The Acquaintance Description Form. In S. F. Duck G. \& D. Pearlman (Eds.), Understanding personal relationships: An interdisciplinarian approach. London: Sage.

Wright, P. H., \& Scanlon, M. B. (1991). Gender role orientations and friendship: Some attenuation, but gender differences abound. Sex Roles, 24, 551-566. 